\title{
Comparative effect of iso-osmolar versus low-osmolar contrast media on the incidence of contrast-induced acute kidney injury in diabetic patients: a systematic review and meta-analysis
}

Fei Zhao ${ }^{1 \dagger}$, Rong Lei ${ }^{2 \dagger}$, Shi-Kun Yang ${ }^{3}$, Min Luo ${ }^{1}$, Wei Cheng ${ }^{1}$, Ye-Qing Xiao ${ }^{1}$, Xu-Wei Li ${ }^{1}$, Jun Guo ${ }^{1}$ and Shao-Bin Duan ${ }^{1 *}$

\begin{abstract}
Background: Contrast-induced acute kidney injury (CI-AKI) is a major adverse effect caused by intravascular administration of iodinated contrast medium. Whether there is a difference in $\mathrm{Cl}$-AKI incidence between iso-osmolar (IOCM) and low-osmolar contrast media (LOCM) among diabetic patients is controversial.

Methods: Randomized controlled trials comparing the nephrotoxic effects between IOCM and LOCM in diabetic patients with or without CKD $\left(e G F R<60 \mathrm{ml} / \mathrm{min} / 1.73 \mathrm{~m}^{2}\right)$ were included in the analysis. The incidence of CI-AKI was defined as an initial increase in serum creatinine ( $\mathrm{SCr}$ ) concentration of at least $0.5 \mathrm{mg} / \mathrm{dl}$ or a rise in creatinine of $25 \%$ from baseline.

Results: A total of 2190 patients were included, among whom 1122 patients received IOCM and 1068 received LOCM. When compared to LOCM, IOCM had no significant benefit in preventing CI-AKI (OR = 1.66, [Cl: 0.97-2.84], $P=0.06, I^{2}=54 \%$ ). However, the difference between IOCM and LOCM was found when CI-AKI was defined as an absolute $\mathrm{SCr}$ increase $(\geq 0.5 \mathrm{mg} / \mathrm{dl})$ rather than a relative $\mathrm{SCr}$ increase $(\geq 25 \%)$. Further analysis showed that LOCM resulted in more adverse events.

Conclusions: Whether there is a difference of Cl-AKI incidence between IOCM and LOCM in diabetic patients was related to the selected diagnostic criteria. The incidence of adverse events was significantly lower with $1 O C M$ when compared with LOCM. Therefore, we suggest that IOCM may be used in diabetic and CKD (eGFR< $60 \mathrm{ml} / \mathrm{min} / 1.73$ $\mathrm{m}^{2}$ ) patients.
\end{abstract}

Keywords: Acute kidney injury, Diabetes, Contrast media

\section{Background}

Contrast-induced acute kidney injury (CI-AKI) is a severe complication of exposure to iodine contrast media for diagnostic or interventional procedure [1], which accounts for increase in morbidity, mortality, length of stay

\footnotetext{
* Correspondence: duansb528@csu.edu.cn

${ }^{\dagger}$ Fei Zhao and Rong Lei contributed equally to this work.

'Department of Nephrology, The Second Xiangya Hospital, Central South University, 139 Renmin Road, Changsha 410011, Hunan, People's Republic of China

Full list of author information is available at the end of the article
}

and hospitalization cost [2]. Controversy remains whether certain contrast media types with various osmolarities are associated with a lower risk of CI-AKI [3, 4]. Although much progress has been made to improve the quality of contrast media, acute kidney injury after intravascular contrast administration remains a major concern for clinicians.

The literatures contain conflicting reports about whether IOCM is associated with less risk for CI-AKI than LOCM $[3,5]$. According to the international guidelines from both European Society of Urogenital 
Radiology (ESUR) and the Kidney Disease: Improving Global Outcomes guidelines (KIDGO), Both IOCM and LOCM were recommended in patients with increased risk of CI-AKI [6, 7]. Diabetic (DM) is one of the most important public health challenges in the twenty-first century. [8]. The risk for CI-AKI is significantly increased in patients with chronic kidney disease (CKD), especially when DM coexists [9]. Several studies have focused on the nephrotoxic comparison between IOCM and LOCM in diabetic patients $[3,10,11]$. However, there are still uncertainties on whether there are any significant differences in renal safety between IOCM and LOCM.

We performed a systematic review of randomized, controlled trials (RCTs) to compare the effects of IOCM and LOCM on CI-AKI incidence and the adverse effects in diabetic patients with or without CKD. We hypothesized that with more recent RCTs included in our updating reviews, we could better understand the conflicting results on CI-AKI risk. To our knowledge, this is the first meta-analysis reporting difference in CI-AKI between IOCM and LOCM among DM patients with or without CKD (eGFR $<60 \mathrm{ml} / \mathrm{min} / 1.73 \mathrm{~m}^{2}$ ).

\section{Methods}

\section{Data collection and search strategy}

A literature review on published RCTs was performed using PubMed, the Cochrane Library, and Web of Science until June 2017. Search keywords included "iso-osmolar", "iodixanol", "visipaque", "IOCM" and "diabetes" as $\mathrm{MeSH}$ and free text terms. In addition, root variations of the mentioned keywords were used in order to improve search outcomes. Related articles were used as well to broaden the search, and the computer search was supplemented with manual searches of the reference lists of all retrieved studies, review articles, and conference abstracts. The systematic review was conducted according to the Preferred Reporting Items in Systematic Reviews and Meta-analysis (PRISMA) guidelines [12].

\section{Study selection}

Selected studies included prospective randomized controlled comparisons of CI-AKI incidence between IOCM and LOCM in diabetic patients with or without CKD. We only included full-text articles with at least two arms of parallel comparisons. Non-randomized controlled studies, studies exploring CI-AKI incidence during procedures other than diabetes, editorials, letters to the editor, reviews, animal experimental studies and those only published as conference abstracts were excluded. Two reviewers independently screened titles and abstracts to identify articles for inclusion. If necessary, the full texts of articles were reviewed. Discrepancies remained after reviewing the full-text were resolved by consensus. At random intervals during screening, quality checks were performed to ensure that inclusion criteria were applied in consistence. All researches were limited to studies in humans.

\section{Outcomes}

The primary outcome was the incidence of CI-AKI in subjects receiving IOCM versus LOCM. CI-AKI is defined by an initial increase in $\mathrm{SCr}$ concentration of at least $0.5 \mathrm{mg} / \mathrm{dl}$ or by a relative increase of at least $25 \%$ from baseline within $36-72 \mathrm{~h}$ after exposure. The numbers of adverse events in the two aforementioned groups were the secondary outcome of this study.

\section{Data extraction and quality assessment}

For every included study, information including study characteristics, study population, imaging procedure type, comparisons, results, and statistical analysis were obtained by one researcher. The extracted information was confirmed for accuracy by another researcher. Discrepancies between the two researchers were resolved by consensus. Trial bias risk and quality assessment of all RCTs were conducted according to the Cochrane collaboration criteria, which pay emphasis on evaluating adequacy of sequence generation, allocation sequence concealment, blinding of participants and caregivers, blinding for outcome assessment, incomplete outcome, selective outcome reporting, and other potential bias. Discrepancies were resolved by consensus.

\section{Statistical analysis}

All analyses were performed using Review Manager (RevMan) Version 5.3 for Windows (Oxford, England). Preferred Reporting Items for Systematic Reviews and Meta-analysis Protocols (PRISMA-P) criteria were used for analysis [13]. Continuous and dichotomous variables were compared by the weighted mean difference (WMD) and odds ratio (OR) respectively.

Chi-square and the $\mathrm{I}^{2}$ statistic that describe the percentage of total variation across studies were used to assess heterogeneity. $\mathrm{I}^{2}$ value ranges from $0 \%$ (no heterogeneity) to $100 \%$ (maximal heterogeneity). Chi-square $p$-values of $<0.1$ and $\mathrm{I}^{2}>50 \%$ or 0.5 mean significant heterogeneity. DerSimonian and Laird's random-effect model was applied for analysis when heterogeneity among studied were high. A $P$ value $\leq 0.05$ was considered significant. Publication bias and skewness were evaluated graphically using a funnel plot. Subgroups analyses for comparisons between iodixanol and specific types of LOCM (eg, iohexol) or between specific groups of patients (i.e., those receiving arterial or intravenous injection, use of NAC, volume of contrast media, with or without CKD and those with or without coronary angiography) were outlined before data collection. Post hoc subgroup analyses of 
studies stratified by the definition of CI-AKI (i.e., $>0.5$ $\mathrm{mg} / \mathrm{dL}$ or $>25 \%$ increase from baseline creatine value) were performed when data were available.

\section{Results}

\section{Identification of studies}

Two hundred twenty two potential studies were included in initial search, among which 186 were eliminated based on the titles and abstracts. Remaining articles were identified by scanning through abstracts and excluded based on whether or not including CI-AKI incidence rates in diabetic patients. One article was identified through other references. Fifteen RCTs that compared IOCM to LOCM fulfilled our inclusion criteria (Additional file 1: Figure S1).

\section{Characteristics of selected clinical trials}

All 15 trials used iodixanol as IOCM, iopromide, iopamidol, iohexol, ioversol, and ioxaglate were used as LOCM. Baseline characteristics of the included 15 RCTs were presented in Table 1. All data were acquired from diabetic patients with or without CKD. The definition of CI-AKI differed among the trials. CI-AKI was defined as an absolute

Table 1 Baseline characteristics of all trials

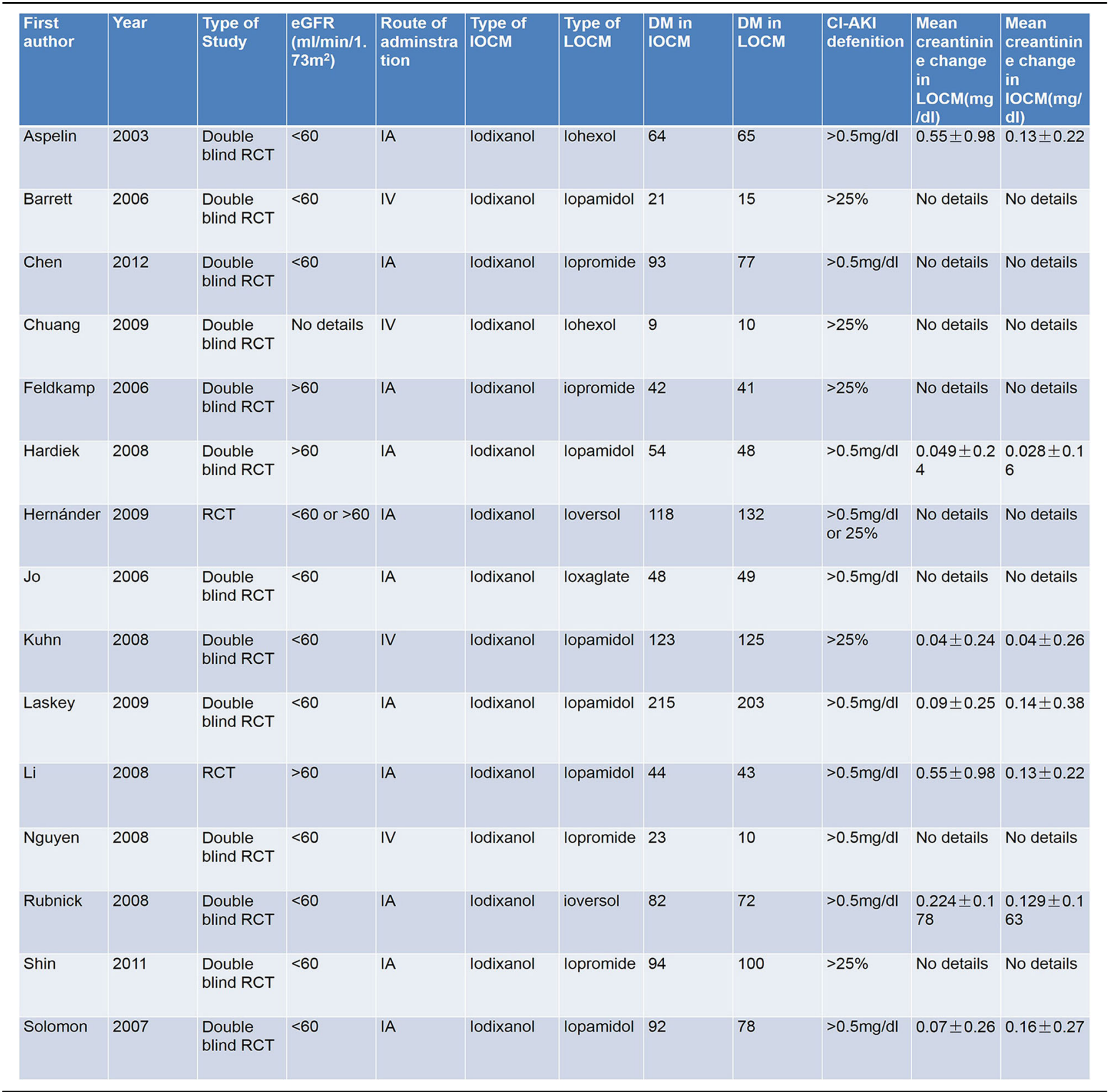


increase of baseline creatinine by at least $0.5 \mathrm{mg} / \mathrm{dl}$ or as a relative increase by at least $25 \%$ in most studies. A few studies used both definitions.

\section{Primary outcome}

To evaluate CI-AKI incidence of IOCM and LOCM in diabetic patients. A total of 2190 patients were included in 15 trials $[3,10,11,14-25]$, among whom 1122 patients used IOCM and 1068 received LOCM. When compared to LOCM, IOCM was not associated with a significantly lower incidence of CI-AKI $(\mathrm{OR}=1.66, \mathrm{CI}$ : $0.97-2.84, P=0.06, \mathrm{I}^{2}=54 \%$ ) (Fig. 1). There was no significant difference of peak increase in one-week serum creatinine between LOCM and IOCM $(P>0.05)$ (Additional file 2: Figure S2). However, the difference between IOCM and LOCM was found when CI-AKI was defined as an absolute $\mathrm{SCr}$ increase $(\geq 0.5 \mathrm{mg} / \mathrm{dl})$ (Fig. 2), rather than a relative $\mathrm{SCr}$ increase ( $\geq 25 \%$ ) (Additional file 3: Figure S3).

We further performed subgroup analysis based on use of different type of LOCM, contrast volume, $\mathrm{N}$-acetylcysteine (NAC), eGFR, route of administration, and the examination of coronary angiography. The subgroups defined before data collection were based on uniformly reported information. No definitive evidence of a difference in CIAKI incidence between different types of LOCM was observed (Additional file 4: Figure S4). There was also no significant difference of CI-AKI incidence in terms of volume of contrast media (Additional file 5: Figure S5). There were emerging data showing that use of NAC had no protective effect in the preprocedural preparations, our study showed similar results (Additional file 6: Figure S6) in diabetic patients. We also found that there was no difference in CIAKI incidence among studies including all CKD patients versus those individuals without CKD (Additional file 7: Figure S7). Furthermore, subgroup analysis based on route of administration (Additional file 8: Figure S8) and the examination of coronary angiography (Additional file 9: Figure S9) did not show any statistically significant difference.

\section{Secondary outcome}

To evaluate adverse events induced by IOCM and LOCM in diabetic patients, we selected 7 studies including adverse events. The results showed that there was lower risk of adverse events in IOCM, compared with LOCM in diabetic patients (Fig. 3).

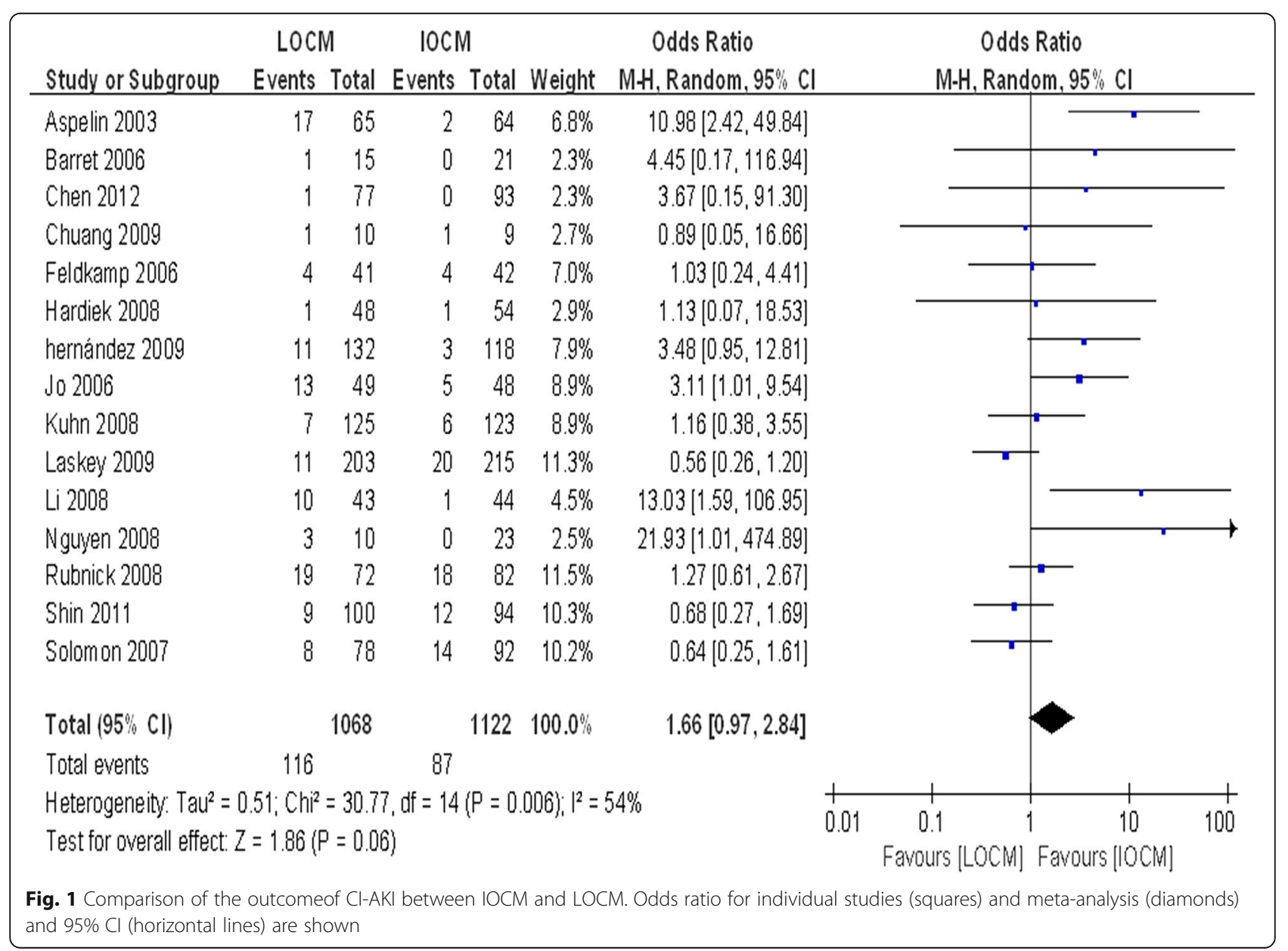




\begin{tabular}{|c|c|c|c|c|c|c|c|c|c|c|}
\hline Studv or Subgroup & $\begin{array}{l}\text { LoCM } \\
\text { Events }\end{array}$ & Total & $\begin{array}{l}10 \mathrm{~cm} \\
\text { Events }\end{array}$ & Total & Weight & $\begin{array}{c}\text { Odds Ratio } \\
\text { M-H, Random, } 95 \% \mathrm{Cl}\end{array}$ & & $\begin{array}{r}\text { Odds } \\
\text { M-H, Rando }\end{array}$ & $\begin{array}{l}\text { Ratio } \\
\text { om. } 95 \% \mathrm{Cl}\end{array}$ & \\
\hline Aspelin 2003 & 17 & 65 & 2 & 64 & $14.0 \%$ & $10.98[2.42,49.84]$ & & & $\because$ & \\
\hline Chen 2012 & 1 & 77 & 0 & 93 & $6.1 \%$ & $3.67[0.15,91.30]$ & & & & \\
\hline Hardiek 2008 & 1 & 48 & 1 & 54 & $7.4 \%$ & $1.13[0.07,18.53]$ & & & & \\
\hline Jo 2006 & 13 & 49 & 5 & 48 & $16.8 \%$ & $3.11[1.01,9.54]$ & & & & \\
\hline Laskey 2009 & 11 & 203 & 20 & 215 & $19.3 \%$ & $0.56[0.26,1.20]$ & & & & \\
\hline Li 2008 & 10 & 43 & 1 & 44 & $10.4 \%$ & $13.03[1.59,106.95]$ & & & & \\
\hline Nguyen 2008 & 3 & 10 & 0 & 23 & $6.5 \%$ & $21.93[1.01,474.89]$ & & & & \\
\hline Rubnick 2008 & 19 & 72 & 18 & 82 & $19.4 \%$ & $1.27[0.61,2.67]$ & & & . & \\
\hline Total $(95 \% \mathrm{Cl})$ & & 567 & & 623 & $100.0 \%$ & $2.77[1.09,7.05]$ & & & & \\
\hline Total events & 75 & & 47 & & & & & & & \\
\hline \multicolumn{7}{|c|}{$\begin{array}{l}\text { Heterogeneity: } \text { Tau }^{2}=1.03 ; \mathrm{Chi}^{2}=22.71, \mathrm{df}=7(\mathrm{P}=0.002) ; \mathrm{I}^{2}=69 \% \\
\text { Test for overall effect: } Z=2.13(P=0.03)\end{array}$} & 0.01 & $\begin{array}{cc}0.1 & 1 \\
\text { Favours [LOCM] }\end{array}$ & $\begin{array}{c}10 \\
\text { Favours }[10 \mathrm{Cm}]\end{array}$ & 100 \\
\hline
\end{tabular}

Fig. 2 IOCM vs. LOCM for the outcome of Cl-AKI (defined by an initial increase in SCr concentration of at least $0.5 \mathrm{mg} / \mathrm{dl}$ within 36-72 h of exposure). Odds ratio for individual studies (squares) and meta-analysis (diamonds) and 95\% Cl (horizontal lines) are shown

\section{Investigation of heterogeneity and publication bias}

We performed subgroup analysis to explore the effect of IOCM and LOCM on CI-AKI incidence, the analysis was stratified according to patients' characters and other factors. In brief, there was no significant difference of CIAKI incidence between IOCM and LOCM. Funnel plots for some key outcomes (Additional file 12: Table S1) suggested there was publication bias among these studies (Additional files 10 and 11: Figures S10-S11.

\section{Discussion}

This meta-analysis of 15 RCTs including 2190 patients comparing the effect between IOCM and LOCM on the incidence of CI-AKI in diabetic patients shown that the use of IOCM has no significant benefit over LOCM in preventing CI-AKI in diabetic patients with or without CKD when CI-AKI was defined as an absolute $\mathrm{SCr}$ increase $(\geq 0.5 \mathrm{mg} / \mathrm{dl})$ or a relative $\mathrm{SCr}$ increase $(\geq 25 \%)$. However, when CI-AKI was defined as an absolute increase of $\mathrm{SCr}(\geq 0.5 \mathrm{mg} / \mathrm{dl})$, the CI-AKI incidence of
IOCM was lower than that of LOCM. More importantly, IOCM was associated with lower risk of adverse events, compared with LOCM.

CI-AKI is a major adverse effect caused by intravascular administration of iodinated contrast media. In the NEPHRIC trial, more than 130 patients who had CKD and DM performing angiography were prospectively randomized to receive either iodixanol or iohexol, iodixanol is a safer agent, at least in those at higher risk of CI-AKI (defined by an initial increase in SCr level $\geq 0.5$ $\mathrm{mg} / \mathrm{dl}$ ), such as those with chronic renal failure due to diabetes mellitus [3]. In contrast, other studies demonstrated that there existed no significant difference in CIAKI incidence (defined by an initial increase in $\mathrm{SCr}$ level $\geq 0.5 \mathrm{mg} / \mathrm{dl}$ ) between IOCM and LOCM in high risk patients [11]. Studies comparing nephrotoxicity of IOCM and LOCM reported a controversial conclusion [26-28]. A prior meta-analysis suggested that IOCM had no significant difference in the incidences of postprocedure hemodialysis or death over LOCM [29]. Our

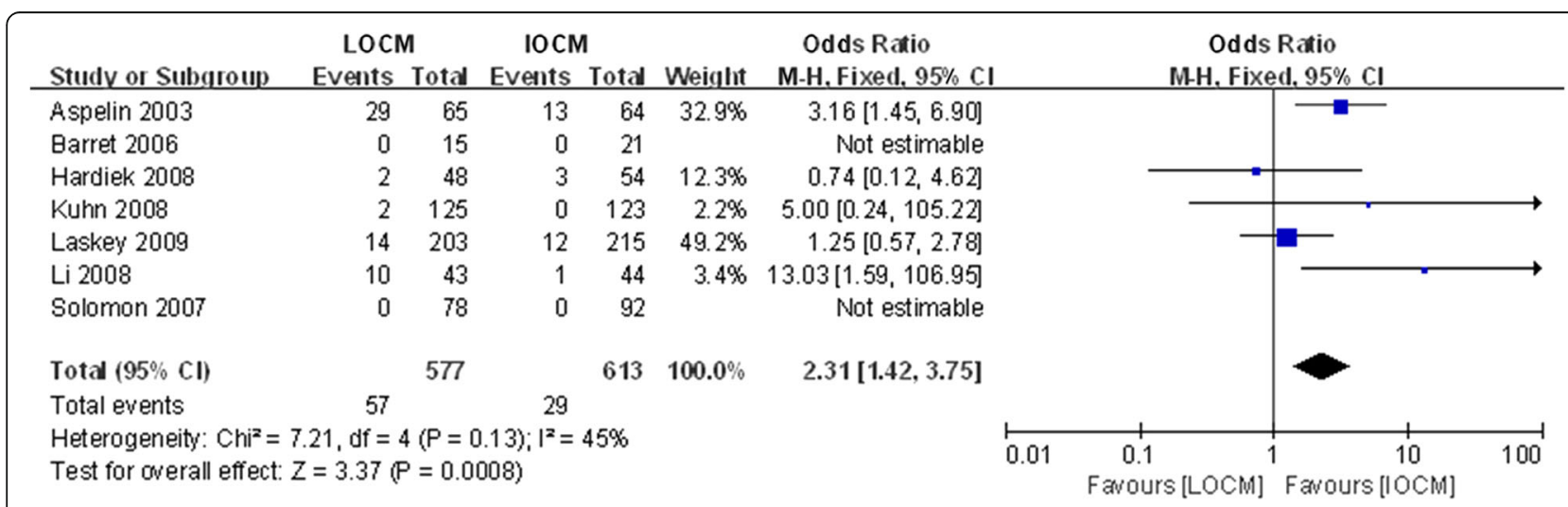

Fig. 3 IOCM vs. LOCM for the outcome of adverse events. Odds ratio for individual studies (squares) and meta-analysis (diamonds) and $95 \% \mathrm{Cl}$ (horizontal lines) are shown 
meta-analysis found no statistical significance of CI-AKI risk with iodixanol compared with LOCM in diabetic patients based on two diagnostic criteria. But IOCM seems safer when referring to an absolute $\mathrm{SCr}$ increase and adverse events which indicated that LOCM indeed had an increased nephrotoxic potential compared to iodixanol. Therefore, our results indicated IOCM would be safer in diabetic and CKD patients. Whether there is a significant difference of LOCM and IOCM induced AKI is related with the use of different diagnostic criteria.

We further did subgroup analysis. In the meta-analysis, we did not see any definitive evidence showing difference in CI-AKI incidence between IOCM and LOCM regardless of patient characteristics (with or without CKD) or contrast media volume. Our study confirmed the result from Kooiman et al. that there seemed to be no association between volume of contrast media and CI-AKI [30]. As other studies, use of IOCM showed non-significant benefit in preventing CI-AKI when compared to LOCM in high risk patients $[21,28]$. We also found no difference in CI-AKI risk with iodixanol compared with a diverse group of LOCM. However, Reed et al. found iodixanol had a lower CI-AKI incidence when compared with iohexol or ioxaglate, similar result was not obtained between the comparison of IOCM with iopromide, iopamidol, iomeprol, or ioversol [31]. The possible reasons may be that different types of patients were included. Subgroup analysis based on administration route showed the pooled relative risk for the intra-arterial route was 1.57 (CI, 0.82-3.03; $P=0.17$ ) and $1.99(\mathrm{CI}, 0.58-6.87 ; P=$ 0.27 ) for the intravenous route, suggesting no difference in CI-AKI risk between route of administration. This result was consistent with Eng J's findings [32]. NAC has long been used as a method to prevent CI-AKI. However, our results indicated that use of NAC showed no protective effect of CI-AKI in diabetic patients, which were similar with other studies [33, 34]. A recent study showed ionic LOCM ioxaglate was associated with a numerically lower one-year mortality than iodixanol in patients with cardiac catheterization [35], which were inconsistent with our results. Therefore, future studies evaluating long-term safety following exposure to different types of contrast media in diabetic patients are warranted.

\section{Strength and limitations}

Up to date, this is the first systematic review and metaanalysis making comparison between IOCM and LOCM on renal safety in diabetic patients. All included studies are RCTs, accounting for very low risk of selection bias. Despite the comprehensiveness and the robust statistical methods in our study, we still have some limitations. First, results of our study are based on the combined data of many heterogeneous randomized, controlled trials. Second, varied definitions of CI-AKI were used in some studies, however, we used only standard definitions according to KDIGO or ESUR guidelines. Third, data could not be fully extracted because of missing information as in any meta-analysis. We tried to contact the studies' corresponding authors but unfortunately failed. At last, there were evidences of publication bias in some of the subgroup analysis, and therefore the results should be interpreted with caution. The number of included RCTs was limited by the presence of literatures comparing effects of IOCM and LOCM on DM and above inclusion.

\section{Conclusions}

In conclusion, whether there is a difference of CI-AKI incidence between IOCM and LOCM in diabetic patients was related to the selected diagnostic criteria. And the incidence of total adverse events was significantly lower with IOCM when compared with LOCM, such as ischemic stroke events, cardiovascular events, rash, burn sensation in the throat, nausea, vomiting, edema, oliguria, progression to end-stage renal disease and so on. We suggest that IOCM may be used in diabetic and CKD $\left(e G F R<60 \mathrm{ml} / \mathrm{min} / 1.73 \mathrm{~m}^{2}\right)$ patients. This study will provide a scientific guide for clinicians to choose the type of contrast agent in diabetic and CKD patients. However, multi-centers prospective randomized controlled trials are still necessary to evaluate effect of IOCM and LOCM on CI-AKI incidence and long-term outcome in diabetic and CKD patients.

\section{Additional files}

\section{Additional file 1: Figure S1. Flow chart of evidence research and} selection. (TIF $2140 \mathrm{~kb}$ )

Additional file 2: Figure S2. IOCM vs. LOCM for the outcome of oneweek peak SCr increase. Mean difference for individual studies (squares) and meta-analysis (diamonds) and 95\% Cl (horizontal lines) are shown. (TIF $2613 \mathrm{~kb}$ )

Additional file 3: Figure S3. IOCM vs. LOCM for the outcome of Cl-AKI (defined by a relative increase of at least 25\% from baseline within 36-72 h of exposure). Odds ratio for individual studies (squares) and metaanalysis (diamonds) and 95\% Cl (horizontal lines) are shown. (TIF 1747 kb)

Additional file 4: Figure S4. IOCM vs. LOCM for the outcome of CI-AKI: subgroup analysis based on different types of LOCM. Odds ratio for individual studies (squares) and meta-analysis (diamonds) and 95\% Cl (horizontal lines) are shown. (TIF $11257 \mathrm{~kb}$ )

Additional file 5: Figure S5. IOCM vs. LOCM for the outcome of Cl-AKI: subgroup analysis based on contrast of volume. Mean difference for individual studies (squares) and meta-analysis (diamonds) and 95\% Cl (horizontal lines) are shown. (TIF 2726 kb)

Additional file 6: Figure S6. IOCM vs. LOCM for the outcome of Cl-AKI: subgroup analysis based on using of NAC. Odds ratio for individual studies (squares) and meta-analysis (diamonds) and 95\% Cl (horizontal lines) are shown. (TIF $3317 \mathrm{~kb}$ )

Additional file 7: Figure S7. IOCM vs. LOCM for the outcome of Cl-AKI: subgroup analysis based on eGFR. Odds ratio for individual studies (squares) and meta-analysis (diamonds) and 95\% Cl (horizontal lines) are shown. (TIF $3727 \mathrm{~kb}$ ) 
Additional file 8: Figure S8. IOCM vs. LOCM for the outcome of CI-AKI: subgroup analysis based on route of administration. Odds ratio for individual studies (squares) and meta-analysis (diamonds) and 95\% Cl (horizontal lines) are shown. (TIF $3626 \mathrm{~kb}$ )

Additional file 9: Figure S9. IOCM vs. LOCM for the outcome of CI-AKI: subgroup analysis based on whether or not CAG was performed. Odds ratio for individual studies (squares) and meta-analysis (diamonds) and 95\% Cl (horizontal lines) are shown. (TIF $3397 \mathrm{~kb}$ )

Additional file 10: Figure S10. Risk of bias summary: review authors' judgements about each risk of bias item for each included study (TIF $4669 \mathrm{~kb})$

Additional file 11: Figure S11. Risk of bias graph: review authors' judgements about each risk of bias item presented as percentages across all included studies. (TIF $8393 \mathrm{~kb}$ )

Additional file 12: Table S1. Effect of IOCM and LOCM on CI-AKI incidence among diabetic patients. (TIF $2221 \mathrm{~kb}$ )

\section{Abbreviations}

CAG: Coronary angiography; Cl: Confidence interval; Cl-AKI: Contrast-induced acute kidney injury; CKD: Chronic kidney disease; DM: Diabetes mellitus; eGFR: Estimated glomerular rate; ESUR: European Society of Urogenital Radiology; IA: Intraarterial administration; IOCM: Iso-osmolar contrast media; IV: Intravenous administration; KIDGO: The Kidney Disease: Improving Globa Outcomes; LOCM: Low-osmolar contrast media; NAC: N- acetylcysteine; OR: Odds ratio; PRISMA-P: Systematic reviews and meta-analysis protocols criteria; RCTs: Randomized controlled trials; RevMan: Review Manager; SCr: Serum creatinine; WMD: Weighted mean difference

\section{Acknowledgements}

We thank Ping Yan and Hong-Shen Wang, MD of Central South University for reviewing the manuscript.

\section{Authors' contributions}

FZ and RL conceived the study, searched databases, selected studies, extracted data, and wrote the draft of the manuscript. SKY provided advice on meta-analysis methodology, analyzed the data, and contributing to writing, reviewing, or revising the manuscript. SKY and JG did the statistical analyses. XWL and YQX helped search databases, selected studies, selected studies, extracted and analyzed data, and contributed to writing the manuscript. ML and WC selected studies, contributed to the discussion, and reviewed and edited the manuscript. SBD conceived the study, helped develop search strategies, contributed to the discussion and writing, reviewing, and revising the manuscript. All authors read and approved the final manuscript.

\section{Funding}

This work was supported by the National Natural Science Foundation of China (No. 81570618, 81873607).

\section{Availability of data and materials}

The datasets used and/or analyzed during the current study are available from the corresponding author on reasonable request.

\section{Ethics approval and consent to participate}

Not applicable.

\section{Consent for publication}

Not applicable.

\section{Competing interests}

The authors declare that they have no competing interests.

\section{Author details}

'Department of Nephrology, The Second Xiangya Hospital, Central South University, 139 Renmin Road, Changsha 410011, Hunan, People's Republic of China. ${ }^{2}$ Department of Nephrology, Changsha Central hospital, Changsha 410004, Hunan, People's Republic of China. ${ }^{3}$ Department of Nephrology, The Third Xiangya Hospital, Central South University, Changsha 410013, Hunan, People's Republic of China.
Received: 20 October 2018 Accepted: 4 June 2019

Published online: 18 June 2019

\section{References}

1. Seeliger E, Sendeski M, Rihal CS, Persson PB. Contrast-induced kidney injury: mechanisms, risk factors, and prevention. Eur Heart J. 2012;33(16):2007-15. https://doi.org/10.1093/eurhearti/ehr494.

2. Mehran R, Nikolsky E. Contrast-induced nephropathy: definition, epidemiology, and patients at risk. Kidney Int Suppl. 2006;(100):S11-5. https://doi.org/10.1038/sj.ki.5000368.

3. Aspelin P, Aubry P, Fransson S, Strasser R, Willenbrock R, Berg KJ. Nephrotoxic effects in high-risk patients undergoing angiography. $N$ Engl J Med. 2003:348(6):491-9. https://doi.org/10.1056/NEJMoa021833.

4. Azzalini L, Vilca LM, Lombardo F, Poletti E, Laricchia A, Beneduce A, Maccagni D, Demir OM, Slavich M, Giannini F, Carlino M, Margonato A, Cappelletti A, Colombo A. Incidence of contrast-induced acute kidney injury in a large cohort of all-comers undergoing percutaneous coronary intervention: comparison of five contrast media. Int J Cardiol. 2018; 273(undefined):69-73.

5. Heinrich MC, Haberle L, Muller V, Bautz W, Uder M. Nephrotoxicity of isoosmolar iodixanol compared with nonionic low-osmolar contrast media: meta-analysis of randomized controlled trials. Radiology. 2009;250(1):68-86. https://doi.org/10.1148/radiol.2501080833.

6. Kidney Disease. Improving Global Outcomes (KDIGO) Acute Kidney Injury Work Group KDIGO Clinical Practice Guideline for Acute Kidney Injury. Kidney Int Suppl. 2012:2:1-138.

7. Stacul F, van der Molen AJ, Reimer P, Webb JA, Thomsen HS, Morcos SK, Almen T, Aspelin P, Bellin MF, Clement O, Heinz-Peer G, Contrast Media Safety Committee of European Society of Urogenital R. Contrast induced nephropathy: updated ESUR contrast media safety committee guidelines. Eur Radiol. 2011;21(12):2527-41. https://doi.org/10.1007/s00330-011-2225-0.

8. Zimmet P, Alberti KG, Magliano DJ, Bennett PH. Diabetes mellitus statistics on prevalence and mortality: facts and fallacies. Nat Rev Endocrinol. 2016; 12(10):616-22. https://doi.org/10.1038/nrendo.2016.105.

9. Andreucci M, Faga T, Pisani A, Sabbatini M, Michael A. Acute kidney injury by radiographic contrast media: pathogenesis and prevention. Biomed Res Int. 2014:2014:362725. https://doi.org/10.1155/2014/362725.

10. Hardiek KJ, Katholi RE, Robbs RS, Katholi CE. Renal effects of contrast media in diabetic patients undergoing diagnostic or interventional coronary angiography. J Diabetes Complicat. 2008;22(3):171-7. https://doi.org/10.1016/j.jdiacomp.2006.11.002.

11. Laskey W, Aspelin P, Davidson C, Rudnick M, Aubry P, Kumar S, Gietzen F, Wiemer M. Nephrotoxicity of iodixanol versus iopamidol in patients with chronic kidney disease and diabetes mellitus undergoing coronary angiographic procedures. Am Heart J. 2009;158(5):822-828.e823. https://doi.org/10.1016/j.ahj.2009.08.016.

12. Liberati A, Altman DG, Tetzlaff J, Mulrow C, Gotzsche PC, loannidis JP, Clarke M, Devereaux PJ, Kleijnen J, Moher D. The PRISMA statement for reporting systematic reviews and meta-analyses of studies that evaluate healthcare interventions: explanation and elaboration. Bmj. 2009;339:b2700. https://doi.org/10.1136/bmj.b2700.

13. Shamseer L, Moher D, Clarke M, Ghersi D, Liberati A, Petticrew M, Shekelle P, Stewart LA, Group P-P. Preferred reporting items for systematic review and meta-analysis protocols (PRISMA-P) 2015: elaboration and explanation. Bmj. 2015;349:g7647. https://doi.org/10.1136/bmj.g7647.

14. Barrett BJ, Katzberg RW, Thomsen HS, Chen N, Sahani D, Soulez G, Heiken JP, Lepanto L, Ni ZH, Nelson R. Contrast-induced nephropathy in patients with chronic kidney disease undergoing computed tomography - A double-blind comparison of iodixanol and iopamidol. Investig Radiol. 2006; 41(11):815-21. https://doi.org/10.1097/01.rli.0000242807.01818.24.

15. Feldkamp T, Baumgart D, Elsner M, Herget-Rosenthal S, Pietruck F, Erbel R, Philipp T, Kribben A. Nephrotoxicity of iso-osmolar versus low-osmolar contrast media is equal in low risk patients. Clin Nephrol. 2006;66(5):322-30.

16. Jo SH, Youn TJ, Koo BK, Park JS, Kang HJ, Cho YS, Chung WY, Joo GW, Chae IH, Choi DJ, Oh BH, Lee MM, Park YB, Kim HS. Renal toxicity evaluation and comparison between visipaque (iodixanol) and hexabrix (ioxaglate) in patients with renal insufficiency undergoing coronary angiography: the RECOVER study: a randomized controlled trial. J Am Coll Cardiol. 2006:48(5): 924-30. https://doi.org/10.1016/j.jacc.2006.06.047.

17. Solomon RJ, Natarajan MK, Doucet S, Sharma SK, Staniloae CS, Katholi RE, Gelormini JL, Labinaz M, Moreyra AE. Cardiac angiography in Renally 
impaired patients (CARE) study: a randomized double-blind trial of contrastinduced nephropathy in patients with chronic kidney disease. Circulation. 2007;115(25):3189-96. https://doi.org/10.1161/CIRCULATIONAHA.106.671644.

18. Kuhn MJ, Chen N, Sahani DV, Reimer D, Beek EJ, Heiken JP, So GJ. The PREDICT study: a randomized double-blind comparison of contrast-induced nephropathy after low- or isoosmolar contrast agent exposure. AJR Am J Roentgenol. 2008;191(1):151-7. https://doi.org/10.2214/AJR.07.3370.

19. Li YH, Zhang LL, Zhao CY. Influences of an iso-osmolar versus a low-osmolar contrast media on radiographic contrast nephropathy in high-risk patients. J Clin Rehab Tissue Eng Res. 2008;12(4):683-6.

20. Nguyen SA, Suranyi P, Ravenel JG, Randall PK, Romano PB, Strom KA, Costello P, Schoepf UJ. Iso-osmolality versus low-osmolality iodinated contrast medium at intravenous contrast-enhanced CT: effect on kidney function. Radiology. 2008;248(1):97-105. https://doi.org/10.1148/radiol.2481071484.

21. Rudnick MR, Davidson C, Laskey W, Stafford JL, Sherwin PF. Nephrotoxicity of iodixanol versus ioversol in patients with chronic kidney disease: the Visipaque angiography/interventions with laboratory outcomes in renal insufficiency (VALOR) trial. Am Heart J. 2008;156(4):776-82.

22. Chuang FR, Chen TC, Wang IK, Chuang CH, Chang HW, Chiou TTY, Cheng YF, Lee WC, Chen WC, Yang KD, Lee CH. Comparison of lodixanol and lohexol in patients undergoing intravenous pyelography: A prospective controlled study. Ren Fail. 2009;31(3):181-8. https://doi.org/10.1080/08860220802669636

23. Hernandez F, Mora L, Garcia-Tejada J, Velazquez M, Gomez-Blazquez I, Bastante T, Albarran A, Andreu J, Tascon J. Comparison of iodixanol and ioversol for the prevention of contrast-induced nephropathy in diabetic patients after coronary angiography or angioplasty. Revista espanola de cardiologia. 2009;62(12):1373-80.

24. Shin DH, Choi DJ, Youn TJ, Yoon CH, Suh JW, Kim Kl, Cho YS, Cho GY, Chae ${ }_{\mathrm{H}}$, Kim CH. Comparison of contrast-induced nephrotoxicity of iodixanol and iopromide in patients with renal insufficiency undergoing coronary angiography. Am J Cardiol. 2011;108(2):189-94. https://doi.org/10.1016/j.amjcard.2011.03.019.

25. Chen Y, Hu S, Liu Y, Zhao R, Wang L, Fu G, He Q, Su X, Zheng Y, Qi X, Liu H, Wang J, Gao W, Wang M, Liu S, Zheng X, He B, Yang P, Zhou S, Gao C, Qiu C. Renal tolerability of iopromide and iodixanol in 562 renally impaired patients undergoing cardiac catheterisation: the DIRECT study. Eurolntervention. 2012;8(7):830-8. https://doi.org/10.4244/EIJV817A126.

26. McCullough PA, Bertrand ME, Brinker JA, Stacul F. A meta-analysis of the renal safety of isosmolar iodixanol compared with low-osmolar contrast media. J Am Coll Cardiol. 2006;48(4):692-9. https://doi.org/10.1016/j.jacc.2006.02.073.

27. Eng J, Subramaniam RM, Wilson RF, Turban S, Choi MJ, Zhang A, SuarezCuervo C, Sherrod C, Hutfless S, lyoha EE, Bass EB. Contrast-Induced Nephropathy: Comparative Effects of Different Contrast Media. Rockville (MD): AHRQ Comparative Effectiveness Reviews; 2015.

28. Pandya B, Chalhoub JM, Parikh V, Gaddam S, Spagnola J, El-Sayegh S, Bogin $M$, Kandov R, Lafferty J, Bangalore S. Corrigendum to "contrast media use in patients with chronic kidney disease undergoing coronary angiography: A systematic review and meta-analysis of randomized trials" [Int. J. Cardiol. (2017) 137-144]. Int J Cardiol. 2017;235:205 https://doi.org/10.1016/j.ijcard.2017.03.021.

29. Cantor $E$, Lim $L$. The relative renal safety of iodixanol compared with lowosmolar contrast media. JACC Cardiovasc Intervent. 2009;2(11):1163-4; author reply 1164. https://doi.org/10.1016/j.jcin.2009.08.022.

30. Kooiman J, Pasha SM, Zondag W, Sijpkens YW, van der Molen AJ, Huisman MV, Dekkers OM. Meta-analysis: serum creatinine changes following contrast enhanced CT imaging. Eur J Radiol. 2012;81(10):2554-61. https://doi.org/10.1016/j.ejrad.2011.11.020.

31. Reed M, Meier P, Tamhane UU, Welch KB, Moscucci M, Gurm HS. The relative renal safety of iodixanol compared with low-osmolar contrast media: a meta-analysis of randomized controlled trials. JACC CardiovasC Intervent. 2009;2(7):645-54. https://doi.org/10.1016/j.jcin.2009.05.002.

32. Eng J, Wilson RF, Subramaniam RM, Zhang A, Suarez-Cuervo C, Turban S, Choi MJ, Sherrod C, Hutfless S, lyoha EE, Bass EB. Comparative effect of contrast media type on the incidence of contrast-induced nephropathy: A systematic review and meta-analysis. Ann Intern Med. 2016;164(6):417-24. https://doi.org/10.7326/M15-1402.

33. Kang $X$, Hu DY, Li CB, Ai ZS, Peng A. N-acetylcysteine for the prevention of contrast-induced nephropathy in patients with pre-existing renal insufficiency or diabetes: a systematic review and meta-analysis. Ren Fail. 2015;37(10):297-303. https://doi.org/10.3109/0886022X.2015.1012985.

34. Anderson SM, Park ZH, Patel RV. Intravenous N-acetylcysteine in the prevention of contrast media-induced nephropathy. Ann Pharmacother. 2011;45(1):101-7. https://doi.org/10.1345/aph.1P275.

35. Giustino G, Baber U, Mastoris I, Vlachojannis GJ, Yu J, Teirstein PS, Downey WE, Batchelor WB, Casterella PJ, Nikolsky E, Wong SC, Theodoropoulos KN, Dangas GD, Mehran R. One-year results of the ICON (ionic versus non-ionic contrast to obviate worsening nephropathy after angioplasty in chronic renal failure patients) study. Catheter Cardiovasc Interv. 2016;87(4):703-9. https://doi.org/10.1002/ccd.26106.

\section{Ready to submit your research? Choose BMC and benefit from:}

- fast, convenient online submission

- thorough peer review by experienced researchers in your field

- rapid publication on acceptance

- support for research data, including large and complex data types

- gold Open Access which fosters wider collaboration and increased citations

- maximum visibility for your research: over $100 \mathrm{M}$ website views per year

At BMC, research is always in progress.

Learn more biomedcentral.com/submissions 